\title{
KEKUATAN POLITIK PEMANGKU ADAT AMMATOA PADA MASYARAKAT ADAT DI TANATOA BULUKUMBA
}

\author{
Gustiana A. Kambo \\ Ilmu Politik, FISIP, Universitas Hasanuddin Makassar \\ *Korespondensi: gustianakambo@yahoo.com
}

\begin{abstract}
This study aims to describe the Existence of the Ammatoa Indigenous Community and the legitimacy of the Ammatoa Political power. This research is descriptive-analytical, the determination of informants is carried out purposively and through interviews and literature review. The developed data describes, describes and analyzes in detail the culture and customs based on the research objectives. The results of the study describe Ammatoa traditional stakeholders who have political power in carrying out their functions as traditional leaders in the indigenous peoples of Tanatoa Bulukumba. Ammatoa acts as an informal leader who also functions as a community leader who has charisma that has more value than others. In every general election, Ammatoa has great influence, the candidates who will participate in the constellation come to Ammatoa to ask for his blessing and hope that his influence will gain his support in Tanatoa with the indigenous people.
\end{abstract}

Kata kunci: Power, holder, custom, charismatic

\begin{abstract}
ABSTRAK
Penelitian ini bertujuan untuk mendeskripsikan Eksistensi Komunitas Adat Ammatoa dan legitimasi kekuatan Politik Ammatoa. Penelitian ini bersifat deskriptif-analisis, penentuan informan dilakukan secara purposive dan dilakukan melalui wawancara dan kajian pustaka. Data dikembangkan menjelaskan, menguraikan dan menganalisis secara rinci budaya dan adat istiadat berdasarkan tujuan penelitian. Hasil penelitian menggambarkan pemangku adat Ammatoa yang memiliki kekuatan politik dalam menjalankan fungsinya sebagai pemimpin adat pada masyarakat adat di Tanatoa Bulukumba. Ammatoa sebagai pemimpin informal berfungsi sebagai tokoh masyarakat yang memiliki kharisma dan nilai lebih dibanding lainnya. Disetiap pemilihan umum, Ammatoa memiliki pengaruh besar, para calon yang akan ikut dalam konstalasi tersebut mendatangi Ammatoa untuk meminta restu dan berharap pengaruhnya untuk mendapat dukungannnya di Tanatoa bersama masyarakat adatnya.
\end{abstract}

Keywords: Kekuatan, pemimpin, adat, kharismatik

\section{PENDAHULUAN}

Masyarakat adat (Indigenous peoples) yang terbentuk dari sebuah etnik biasanya merupakan komunitas yang hidup secara mandiri, dengan mengatur dan mengurus dirinya. Dalam hal ini, komunitas tersebut merupakan kelompok yang memiliki perbedaan dengan kelompok lainnya. Selain itu, mereka 
ISSN: 2614-4336

VDL. 7 No. 1 HAL. 90-99

biasanya membentuk etnisitas yang merujuk pada rasa "kekitaan" yang menyatukan anggotanya dengan sejarah,nilai, sikap dan tingkah laku yang sama dan merasa jauh lebih baik dan hebat daripada kelompok lain.

\section{Dalam sifatnya yang cenderung} menganggap kebudayaan kelompoknya adalah pusat segalanya dari kelompok mereka, tidak dapat dipungkiri besarnya peran yang dijalankan oleh pemimpin dari kelompok tersebut. Sumber utama berasal dari kekuatan pemimpin tanah adat yang dianggap sebagai wakil Tuhan (Syafa'at, Rachmad.dkk 2008). Posisi tersebut berlangsung selama keberadaan kelompok etnik dan kemampuan dari kelompok tersebut untuk mempertahankan tradisi yang telah lama dianutnya termasuk menjadi penguat legitimasi pemerintah, ketika pemangku adat sebagai tokoh masyarakat memasuki ruang kehidupan politik, kecendrungan kepemimpinannya pula mengarah pada sifat yang pragmatis. Situasi tersebut akan membangunkekuatan politik di tingkat lokal dan menciptakan ruang politik bagi pemangku adat. Kekuatan pemangku adat yang terbangun dari kelompoknya menjadikan mereka dengan penamaaannya sebagai kelompok dengan sistem social politik yang khas, misalnya pada Masyarakat Ammatoa (yang disebut dengan Orang Kajang Dalam) di Bulukumba di Sulawesi Selatan. Penamaan Ammatoa bukanlah merupakan nama diri melainkan nama jabatan atau panamaan sesuai dengan statusnya, Amma adalah istilah bahasa konjo yang artinya bapak, sedang istilah toa artinya tua, sehingga Ammatoa dimaknai sebagai bapak tua atau yang di tuakan (Alim, 2005).

Pemangku adat memiliki hubungan emosional dengan masyarakatnya, maka diharapkan mampu mengakomodir semua aturan yang dikeluarkan oleh pemerintah termasuk keikutsertaan dalam pemilihan kepala daerah. Pemilihan umum dipahami sebagai sebuah sistem yang menjadi karakteristik demokrasi modern. Walaupun Pemilu bersifat modern dan diterima oleh suku Tanatoa, akan tetapi ritual adat harus dilaksanakan oleh Ammatoa, yaitu dengan meminta izin pada leluhur untuk meminta petunjuk sosok pemimipin yang pantas yang harus dipilih sesuai dengan pasang ri kajang. Kekuasaan Ammatoa bukanlah jabatan yang sarat dengan kekuasaan dan kekayaan, tetapi posisi kehormatan yang sarat dengan tanggungjawab untuk melindungi tanah, penduduk, keamanan, 
ISSN: 2614-4336

VDL. 7 No. 1 HAL. 90-99

hubungan-hubungan sosial, dan sebagainya, sehingga Ammatoa sangat besar mempengaruhi masyarakat suku setempat untuk mengikuti pilihan politiknya sesuai amanah yang di sampaikannya (Pelras:1981).

Pada hakekatnya makna kekuatan selalu berdimensi berdiri sendiri, akan tetapi keberadaan kekuatan dapat dilihat dari relasi antara individu yang terkait dengan orang lain, sehingga kekuatan itu dapat mempengaruhi dan dapat dipengaruhi. Pengaruh yang masuk terkadang tampak seperti ingin memperkuat individu yang bersangkutan, namun sesungguhnya memiliki potensi melakukan pengrusakan terhadap kekuatan (Rieke, 2004:60). Sementara itu dalam pemaknaannya, kekuatan politik lebih berfokus pada kapasitas yang dimiliki seseorang untuk mempengaruhi atau berusaha mengubah perilaku orang lain sehingga mau melakukan sesuatu, yang dia sendiri tidak memiliki pilihan lain untuk tidak melakukannya (Budiarjo:1988).

Menurut Hannah Arendndt kekuatan (strength) merupakan sifat atau karakter yang di miliki setiap individu. Pada hakekatnya kekuatan berdiri sendiri, namun keberadaan kekuatan dapat dilihat dari relasi antara individu terkait dengan orang lain. Karena itu kekuatan dapat dipengaruhi. Individu yang sangat kuat dapat juga terpengaruh.Pengaruh yang masuk terkadang tampak seperti ingin memperkuat individu yang bersangkutan, namun sesungguhnya memiliki potensi melakukan pengrusakan terhadap kekuatan (Rieke, 2004:60).

Dalam pemaknaan yang lebih luas, kekuatan politik mengandung dua posisi, yaitu dalam pengertian individual maupun dalam pengertian kelembagaan. Dalam pengertian yang bersifat individual, kekuatan- kekuatan politik tidak lain adalah aktor-aktor politik atau orang-orang yang memainkan peranan dalam kehidupan politik. Orang-orang ini terdiri dari pribadi- pribadi yang hendak mempengaruhi proses pengambilan keputusan politik. Dalam pengertian kelembagaan, kekuatan politik sebagai lembaga atau organisasi ataupun bentuk lain yang melembaga dan bertujuan untuk mempengaruhi proses pengambilan keputusan dalam sistem politik (Budiarjo, 1988:52).

Dalam pengertian kekuatan politik secara kelembagaan yang menyangkut pada organisasai atau bentuk lain yang 
ISSN: 2614-4336

VDL. 7 No. 1 HAL. 90-99

melembaga, tidaklah salah jika kekuatan politik dapat terbentuk dari kelompok masyarakat dari sebuah komunitas yang melembaga dalam kelompoknya sendiri, seperti kelompok etnik. Kekuatan politik dari kelompok etnik dapat dikenal berbarengan dengan kemunculannya, yaitu: pertama, kelompok etnik secara biologis berkembang biak dan bertahan; kedua, memiliki nilai-nilai budaya yang sama dan sadar akan kebersamaan dalam suatu bentuk budaya, dan ketiga; membentuk jaringan komunikasi dan interaksi sendiri, dan menentukan ciri kelompok lain dan dapat dibedakan dari kelompok populasi lain (Barth,1998:11).

Pandangan lain dikemukakan oleh Rothschild yang menyebutkannya sebagai Ethnopolitic mengasumsikan politik etnik sebagai: Pertama, membuat seseorang mengetahui dan sadar akan ketertarikan politik dengan nilai-nilai budaya etnik mereka dan sebaliknya; Kedua, untuk mendorong perhatian khalayak mengenai keterkaitan kedua nya anatara politik dan etnik; Ketiga, untuk memobilisasi mereka kedalam keadaan etniknya; dan Keempat, mengarahkan perilaku mereka kedalam aktivitas karena pada basis kesadaran, perhatian dan kesadaran kelompok. Politisisasi etnik seperti itu bisa meningkatkan, memperlambat, atau mendelegitimasi sistem politik; menstabilkan atau bahkan mengikis pemerintahan dan rezim mereka (Barth:1998). Pelaksanaan politik etnik biasanya dilekatkan pada orang atau sebagaian orang. Hal ini dapat ditunjukkan pada kegiatan yang dilakukannya dan seberapa besar pengaruhnya yang ditimbulkan dari proses tersebut.

Dalam membahas relasi kekuatan politik yang dimiliki Ammatoa. Penelitian ini membahas keberadaan pemangku adat dalam pemanfaatan kekuatannya sebagai pemegang kekuasaan wilayah untuk mempengaruhi kehidupan masyarakat adatnya termasuk dalam pilihan politik masyarakat adatnya untuk memilih calon yang sama dalam pemiilihan kepala daerah.

\section{METODE}

Penelitian ini bersifat deskriptifanalisis, penentuan informan dilakukan secara purposive dan pengumpulan data dilakukan melalui wawancara dan kajian pustaka. Wawancara mendalam menggunakan pedoman wawancara (interview guide) agar wawancara tetap berada pada fokus penelitian, meski tidak menutup kemungkinan terdapat pertanyan- 
ISSN: 2614-4336

VDL. 7 No. 1 HAL. $90-99$

pertanyaan berlanjut. Informan yang dipilih adalah infoman yang benar paham dan mengetahui permasalahan yang di maksud. Informan yang penulis wawancarai untuk pengumpulan data ini terdiri dari komponen masyarakat adat dan beberapa orang terkait diluar kawasan Tanatoa.

\section{HASIL DAN PEMBAHASAN}

\section{Eksistensi Komunitas Adat Ammatoa}

Komunitas Adat Ammatoa Masyarakat Desa Tana Toa Kecamatan Kajang Kabupaten Bulukumba adalah merupakan salah satu kelompok masyarakat adat yang sehari-harinya berbahasa Konjo (dialek yang digunakan di kajang) dan tetap memegang tradisinya. Dalam kawasan adat, pakaian menjadi ciri khas tersendiri. Masyarakatnya memakai pakaian serba hitam dan tidak memakai pengalas kaki serta bagi laki-laki yang sudah berkeluarga atau sudah memiliki ciri seorang pemimpin, maka sudah pantas memakai "Passapu" (pengikat kepala, mahkota). Inilah salah satu tradisi yang tetap bertradisi secara turun temurun. Selain pakaian hitam, pakaian yang berwarna mencolok seperti warna kuning, orange, merah dan lain-lain itu menjadi pantangan dan tidak boleh dipakai (ada rahasia dibalik rahasia) (Husain, dkk. 2009). Warna hitam memiliki makna sebagai simbol kesederhanaan, kesamaan dalam bentuk wujud lahir, menunjukkan kekuatan, kesamaan derajat bagi setiap orang serta peringatan kepada masyarakat akan adanya kematian.

Komunitas Ammatoa di Kajang merupakan salah satu komunitas adat di Indonesia yang hutannya masih terlindungi. Mereka tetap berpegang teguh pada "Pasang ri Kajang" (sistem nilai budaya komunitas Ammatoa) yang merupakan ajaran dari leluhur yang berasal dari Tu Rie' A'ra'na (Tuhan) melalui Ammatoa sebagai pimpinan komunitas tertinggi. Pasang merupakan pesan-pesan, petuah-petuah, petunjuk-petunjuk dan aturan-aturan bagaimana seseorang menempatkan diri terhadap makro dan mikro kosmos serta tata cara menjalin harmonisasi alam-manusia-Tuhan. Pasang menjadi ukuran apakah sesuatu itu "baik" atau "buruk" atau apakah sesuatu itu "boleh" atau "tidak" (Hijjang, 2005).

Pasang (pesan) menganjurkan agar tidak merusak hutan karena komunitas Ammatoa memandang hutan sebagai sumber kehidupan dan penyangga keseimbangan lingkungan. Bagi komunitas 
ISSN: 2614-4336

VDL. 7 No. 1 HAL. $90-99$

Ammatoa jika hutan rusak, maka rusak pula kehidupan mereka. Oleh sebab itu, komunitas adat Ammatoa sangat berpantang untuk mengganggu hutan dan mengambil kayunya (Yusuf:2012). Dalam upaya menjaga kelestarian hutannya, komunitas dibagi menjadi dua wilayah yaitu wilayah ilalang embayya (kawasan lindung yang tidak boleh diganggu) dan wilayah pantarang embayya yang dapat dimanfaatkan oleh komunitas. Dengan adanya batas wilayah yang boleh dimanfaatkan dan yang tidak boleh di manfaatkan, komunitas Ammatoa dapat menjaga kelestarian hutannya sampai sekarang (Fitriani dkk:2003).

Ammatoa menjalankan kepemimpinannya didampingi oleh angrongta (ibu) yang menangani masalah tertentu, selain itu, Ammatoa juga dibantu oleh Karaeng Tallua yang bertugas membantu dalam bidang pemerintahan (ada tanaya). Adapun ada' Limaya adalah membantu Ammatoa yang bertugas mengurusi masalah adat (dewan adat). Karaeng tallua merupakan tri tunggal dalam bidang pamerintahan dan dikenal "tallu karaeng mingka se'reji" (yang disebut dengan sulewetang, labbiriya dan moncong buloa). Ini berarti apabila ada upacara adat dan salah satu orang di antaranya telah hadir dalam upacara adat tersebut, maka karaeng tallu sudah dianggap hadir. Dalam menjalankan peran dan fungsi sebagai pemimpin komunitas, Ammatoa dibantu oleh majelis adat untuk mengurusi berbagai bidang (Hijjang, 2005).

Para pejabat bertanggung jawab langsung kepada Ammatoa berdasarkan adat (manajemen tradisional) yang diatur oleh Ammatoa. Urusan yang berkaitan dengan pemerintahan formal diserahkan sepenuhnya kepada pamerintah daerah, mulai dari tingkat Kepala Desa, Camat, dan seterusnya karena komunitas adat sangat patuh kepada pamerintah. Sebagai orang yang di tuakan, Ammatoa adalah pengayon dan suri teladan bagi semua warga suku. Ia menjadi pelidung (sandro) jika terjadi bambang lantama ujung lantoro. Artinya apabila negeri dilanda wabah penyakit dan bahaya perang.

\section{Legitimasi Kekuatan Politik Ammatoa}

Undang-undang Nomor 5 Tahun 1974 tentang Pemerintahan di Daerah dan Undang-undang Nomor 5 Tahun 1979 tentang Pemerintahan Desa, memungkinkan kekuasaan lembaga adat tidak lagi mempunyai kekuasaan politik 
ISSN: 2614-4336

VDL. 7 No. 1 HAL. $90-99$

yang dominan. Dalam situasi yang demikian, sebagian masyarakat cenderung memilih cara lain untuk memperkuat legitimasi identitasnya demi mencapai kebutuhan hidupnya, seperti menghidupkan kembali ritual-ritual adat istiadat atau taat kepada seseorang yang memiliki karismatik karena diakui dapat melindungi hak-hak dan kebutuhannya. Seiring dengan berlakunya kebijakan desentralisasi, kecenderungan pemangku adat kemudian menjadi alat legitimasi pemerintah oleh seorang tokoh masyarakat. Sehingga kekuatan politik di tingkat lokal kini menciptakan ruang politik bagi pemangku adat kembali sesuai dengan nilai adatnya. Penamaan terhadap masyarakat adat dengan sistem sosial politik yang khas ini berbeda dari satu daerah ke daerah lain.

Ammatoa adalah sosok yang didengar dan dituruti, tetapi oleh pengikutnya tidak dipandang sebagai dewa atau Tuhan yang harus dipuja. Ammatoa adalah manusia biasa yang dalam kalangan pengikutnya mempunyai kelebihan, terutama dalam soal meramal kejadian-kejadian yang akan terjadi pada rakyat Kajang. Sedangkan dalam artian sebagai institusi, ammatoa adalah sebuah lembaga, tempat musyawarah mufakat dalam membahas masalah adat. Lembaga adat Ammatoa mempunyai struktur kelembagaan dan pembagian tanggung jawab yang jelas. Struktur kelembagaan Ammatoa mirip dengan pemerintahan formal dimana Ammatoa berfungsi sebagai pemimpin tertinggi.

Hal ini memperlihatkan kehidupan masyarakat adat itu terdapat struktur yang mengatur kehidupan adat, dimana sesuai dengan pemikiran yang disampaikan oleh Darwis, menyampaikan pendapat tentang Ter Haar, mengenai masyarakat adat yaitu suatu kesatuan manusia yang teratur, mempunyai penguasa dan kekayaan yang berwujud ataupun tidak berwujud. Para anggota kesatuan mengalami kehidupan yang wajar menurut kodrat alam dan tidak seorang pun diantara para anggota itu mempunyai pikiran atau kecenderungan untuk membubarkan ikatan atau meninggalkannya dalam arti melepaskan diri dari ikatan tersebut untuk selamalamanya. Sehingga masyarakat adat pada hakikatnya tidak dapat melepaskan diri hukum adat, karena ketika terdapat masyarakat adat terdapat pula hukum adat yang akan mengaturnya (Ranidar Darwis 2003). 
ISSN: 2614-4336

VDL. 7 No. 1 HAL. $90-99$

Ammatoa merupakan sosok pemimpin yang baik, pemimpin yang penempatannya sangat dituakan. Posisi sebagai ketua adat mengharuskan Ammatoa sebagai pemegang kepemimpinan adat menjalankan dengan baik dan semaksimal mungkin karena mempertahankan posisi tersebut lebih sulit ketimbang mendapatkannya. Peranan yang diberikan oleh seorang ketua adat dalam hal ini Ammatoa diberikan kekuasaan penuh dalam menjalankan peranannya. Peranan tersebut menjadikan sosok Ammatoa yang harus senantiasa sempurna dalam pandangan masyarakat adatnya. Hal ini setidaknya membenarkan tentang danya kedaulatan yang dimemiliki pemimpin sebuah wilayah (setingkat raja). bahwa pemimpin dapat mengganggap dirinya sebagai orang yang di tuakan dan menempatkan diri sebagai seorang raja dan juga dirinya sebagai seorang pemimpin karena kehendak tuhan. Dalam tataran ini, akhirnya pemimpin sebagai pemegang keadilan dan dijadikan dasar dalam mengatur kehidupan warganya.

Peranan pemerintah raja yang dimiliki oleh sosok Ammatoa menjadikannya semakin mudah dalam memobilisasi Masyarakat adatnya. Dalam tradisi yang demikian, ada pengaruh dari luar yang harus juga dihadapi oleh Ammatoa. Kenyataannya bahwa tedapat celah yang dimasuki oleh beberapa peserta pemilu (calon anggota legislative; calon kepala daerah dan calon gubernur) untuk mendekati dan mempengaruhi Ammatoa, Sehingga pengaruh Ammatoa terhadap pilihan masyarakat dalam politik pun sangat besar.

Proses Politik seperti Pemilu yang juga berlangsung di suku Tanatoa, membawa peran yang kuat pula bagi Ammatoa. Kedudukannya menjadi perhatian, terutama bagi para elite yang ikut dalam konstelasi politik. Ammatoa dan masyarakat adatnya menjadi salah satu sasaran yang baik dalam mendulang suara. Oleh karena itu, ketika para elite mendekati dan meminta restu pada Ammatoa untuk ikut berkompetisi dalam pemilu, bagi elite itu merupakan suatu langkah yang tepat.

Selain memobilisasi masyarakat secara langsung Ammatoa sebagai ketua adat menggunakan beberapa cara secara lain yakni menjalankan ritual adat yang sedikit berbau mistis. Peranan ini sudah melewati pemikiran secara rasional disebabkan memakai hal-hal yang berbau mistis yang dilakukan oleh sosok 
ISSN: 2614-4336

VDL. 7 No. 1 HAL. 90-99

Ammatoa untuk memobilisasi masyarakat dan memberikan kekuatan kepadanya agar segala bentuk perkataannya diikuti oleh masyarakat di Tanatoa dan kecamatan Kajang Umumnya. Bentuk-bentuk kekuatan yang dimiliki Ammatoa memberikannya kekuasaan secara penuh selaku pemangku adat di suku Tanatoa. Hal dapat diasumsikan bahwa peranan aturan adat mengikat bukan hanya sebagai kekuatan tunggal yang dimiliki Ammatoa. Sebab adanya faktor mistis jika merupakan alasan lain kekuatan politik yang dimiliki Ammatoa pada masyarakat adatnya.

\section{KESIMPULAN}

Ammatoa dalam kapasitasnya sebagai pemangku adat sangat membantu pemerintah dalam rangka menjalankan roda pemerintahan di desa karena Adat Ammatoa masih sangat dihormati oleh masyarakat setempat. Oleh karena wibawa yang dimiliki oleh lembaga adat ini begitu disegani, maka masyarakat akan taat pada kebijakan yang diambilnya, sehingga membantu pemerintah melaksanakan program kepemerintahan yang baik (good governance).

Peranan sebagai pemangku adat memberikan kekuasaan penuh kepada Ammatoa disuku tanatoa. Kekuasaan yang ia miliki secara langsung menghasilkan kepatuhan penuh masyarakat terhadapnya. Kepatuhan masyarakat terhadap sosok Ammatoa menjadikannya sebagai elit penentu dalam kehidupan masyarakat di suku Tanatoa, termasuk dalam penempatan pilihan politik pada Proses pemilu. Ammatoa memiliki kemampuan membentuk karakter masyarakat dalam memilih. Pemangku adat ini menjadi perhatian dari elit politik local yang ingin memenangkan konstalasi dalam pemilihan umum. karena pengaruhnya yang sangat kuat dalam masyarakat adatnya, apapun yang dikatakan oleh Ammatoa harus diikuti olah masyarakat adatnya.

\section{DAFTAR PUSTAKA}

Alim Katu, Mas, Tasawuf Kajang, Makassar, Pustaka Refleksi, 2005

Barth, Fredik, kelompok-kelompok etnik dan batasannya, (Jakarta, UIPress, 1988)

Budiarjo, Miriam, Dasar Dasar Ilmu Politik. UI Press 1988

Diyah pitaloka, Rieke, kekerasan Negara Menular Ke Masyrakat ,2004.

Edy, Rafael B. Hak-hak Masyarakat Adat dalam Konteks Pengelolaan Sumber Daya Alam. Jakarta: Elsam. 2006.

Fitriani, Andi, Djoko Sukisno. 2003. Eksistensi tanah hak ulayat masyarakat hukum adat Kajang 
ISSN: 2614-4336

VDL. 7 No. 1 HAL. 90-99

dan pengelolaannya di Kabupaten

Bulukumba Sulawesi Selatan.

Perpustakaan Universitas

GadjahMada

Hijjang, Pawennari. Pasang dan Kepemimpinan Ammatoa: Memahami Kembali Sistem Kepemimpinan Tradisional Masyarakat Adat dalam Pengelolaan Sumberdaya Hutan di Kajang Sulawesi Selatan. ANTROPOLOGI INDONESIA Vol. 29, No. 3. Makassar: Universitas Hasanuddin Press. 2005.

Husain, B. Sarkawi dan Sri Endah Kinasih. "Pasang ri Kajang" Pasang sebagai modal sosial (social capital) dalam pengelolaan hutan oleh masyarkat adat Ammatowa, kabupaten Bulukumba, Sulawesi selatan. Laporan Penelitian, Universitas Airlangga. Surabaya. 2009.

Pelras, C. Hubungan Patron Klien dalam Masyarakat Bugis Makassar di Sulawesi Selatan. Melbourne: Jurnal Internasional Monash University Press. 1981.

Ranidar Darwis, S. H. 2003. Peranan Pendidikan dan Lingkungan dalam
Pelaksanaan Hukum Waris Adat Minangkabau pada Masyarakat Perantauannya di Kota Bandung.

Syafa'at, Rachmad.dkk. Negara, Masyarakat adat dan Kearifan Lokal. Malang. In-Trans Publishing. 2008.

Yusuf. Eksistensi Tanah Hak Ulayat dalam Peraturan Perundangundanganan Surabaya. Tesis Universitas Airlangga. 2012.

Undang-undang Nomor 5 Tahun 1974 tentang Pemerintahan di Daerah.

Undang-undang Nomor 5 Tahun 1979 tentang Pemerintahan Desa.

\section{PROFIL SINGKAT}

Dr. Gustiana A. Kambo, M.Si Lahir 13 Agustus 1973. Lulus Sarjana (S1) dari Program Studi S1 Ilmu Politik di Universitas Hasanuddin. Kemudian melanjutkan S2 Ilmu Sosial di Universitas Airlangga dan kemudian meraih gelar Doktor (S3) Ilmu Sosial di Universitas Airlangga. Bidang Kajian Politik Identitas. 